\section{Sistema de Mineralogia Automatizada em apoio à Exploração Mineral}

Silva, F. L. ${ }^{1^{*}}$, Silva, M. R. ${ }^{2}$, Sampaio, N. P. ${ }^{1}$, Araújo, F. G. S. ${ }^{1}$, Tazava, ${ }^{2}{ }^{2}$

${ }^{1}$ REDEMAT, Universidade Federal de Ouro Preto.

${ }^{2}$ Departamento de Geologia, Universidade Federal de Ouro Preto.

Copyright 2016, SBGf - Sociedade Brasileira de Geofísica

Este texto foi preparado para a apresentação no VII Simpósio Brasileiro de Geofísica, Ouro Preto, 25 a 27 de outubro de 2016. Seu conteúdo foi revisado pelo Comitê Tecnico do VII SimBGf, mas não necessariamente representa a opinião da SBGf ou associados. E proibida a reprodução total ou parcial deste material para propósitos comerciais sem prévia autorização da SBGf.

\section{Resumo}

Os sistemas de mineralogia automatizada, constituem a última geração de equipamentos desenvolvidos, que proporcionam análises mineralógicas automáticas, rápidas e precisas. Tal sistema tem por objetivo fazer automaticamente a análise mineralógica de amostras, por comparação dos espectros de raios $X$ característicos de cada partícula, com os espectros característicos de um banco de dados. Especificamente, o equipamento conta com uma interface que permite acrescentar minerais e outros materiais a seu banco de dados básico, o que é fundamental para a acurácia dos resultados. Isto decorre do fato de o banco de dados original do equipamento ter sido criado apenas com amostras minerais oriundas de outros países, de maneira que não são identificados de imediato todos os minerais presentes em nosso território, com seus característicos elementos majoritários e minoritários. A otimização do banco de dados minerais do sistema de mineralogia automatizada permitirá a caracterização precisa, rápida e a baixo custo de nossos bens minerais, em um setor tão importante para a economia brasileira, além de estender o uso do sistema para outros materiais.

\section{Introdução}

Além das técnicas tradicionais, os analisadores minerais integrados, usualmente referidos como sistemas de mineralogia automatizada, constituem a última geração de equipamentos desenvolvidos, que proporcionam análises mineralógicas automáticas, rápidas e precisas. Os referidos sistemas executam análises através da conjugação das técnicas de microscopia eletrônica de varredura e espectrometria de energia dispersiva de raios $\mathrm{X}$ e geram dados consideravelmente mais robustos, no que diz respeito às composições mineralógicas e químicas, às distribuições de elementos e partículas e à determinação dos espectros de liberação mineral (Petruk 1989, Sutherland \& Gottlieb 1991). Inicialmente desenvolvidos para a indústria de mineração, os sistemas de mineralogia automatizada evoluíram substancialmente nas últimas duas décadas, ampliando suas aplicações para as áreas como a geociências e a indústria de petróleo e gás (Haberlah 2011, FEI. 2015).
Este trabalho objetiva, primeiramente, a otimização do banco de dados minerais do sistema de mineralogia automatizada, contemplando, sobretudo, a assembleia mineralógica dos principais minérios brasileiros de interesse econômico - incluindo os minerais de minério e de ganga - através do desenvolvimento de uma metodologia específica de caracterização de minérios. Visando, comprovar a eficácia da sua aplicação aos estudos de análise microestrutural e de caracterização mineralógica, foram estudadas amostras de rejeitos do beneficiamento de minério de ferro.

\section{Metodologia}

A metodologia empregada neste trabalho consistiu na seleção e preparação física de amostras dos rejeitos do beneficiamento de minério de ferro, na identificação por difratometria de raios $X$, na aquisição de dados e no desenvolvimento do banco de dados no sistema de mineralogia automatizada. Para a caracterização mineralógica de amostras de rejeitos de minério de ferro foi utilizado o analisador mineral integrado conhecido como TIMA-MIRA. O sistema de mineralogia automatizada TIMA-MIRA foi especificamente projetado para indústria de mineração e permite rápidas análises mineralógicas quantitativas de rochas, minérios, concentrados, rejeitos, resíduos de lixiviação e produtos de fundição. O sistema constitui-se de um software de controle de varredura e de análise de dados minerais, denominado TIMA, e de um hardware SEM/FEG-EDX integrado, comercialmente conhecido como MIRA, composto por um microscópio eletrônico de varredura, com canhão de elétrons por emissão de campo (FEG Field Emisson Gun), associado a dois detectores de dispersão de energia de raios $X$ característicos [12]. As amostras de rejeitos estudadas foram: de flotação, de separação magnética de grossos e de separação magnética dos finos e deslamagem, na faixa granulométrica $<0,044 \mathrm{~mm}$. Essas amostras foram caracterizadas anteriormente, em termos granulométricos, por meio de ensaios de peneiramento, em termos qualitativos, por difratometria de raios $\mathrm{X} \mathrm{e}$, em termos quantitativos, por minerografia quantitativa.

\section{Resultados}

\section{- Composição Mineralógica Qualitativa}

Para todas as amostras selecionadas foram obtidas imagens de varredura de campo através da aquisição de dados no sistema de mineralogia automatizada, que correspondem aos mapas de distribuição de fases minerais e evidenciam a composição mineralógica da amostra em termos qualitativos. A Figura 1 mostra as imagens mineralógicas das amostras das faixas granulométricas dos rejeito de flotação, de separação magnética de grossos e de separação magnética dos finos e deslamagem, na faixa granulométrica $<0,044 \mathrm{~mm}$. As amostras de rejeitos evidenciam a predominância dos minerais quartzo e hematita além do substancial incremento de magnetita e goethita. Os resultados da análise qualitativa dos rejeitos de minério de ferro 
adquiridos no sistema de mineralogia automatizada estão em concordância com os resultados obtidos através da técnica de difratometria de raios $\mathrm{X}$ como pode ser visto na Figura 2.

\section{- Composição Mineralógica Quantitativa}

Para todas as amostras foram obtidas as composições mineralógicas quantitativa através do relatório de análise mineral mass disponibilizado pelo software do sistema de mineralogia automatizada, no qual as frações de volume foram estimadas a partir do número de pixels identificados em cada fase. A Tabela 1 expõe a composição mineralógica, em termos quantitativos. A composição mineralógica, em termos quantitativos do rejeito de flotação apresenta maior quantidade de quartzo $(67,78 \%)$. Os rejeitos da separação magnética dos grossos, apresenta o menor volume de quartzo $(64,53 \%)$ e os maiores volumes de óxidos e hidróxidos de ferro $(28,58 \%)$ e de minerais acessórios $(6,68 \%)$. Já o rejeito da separação magnética dos finos e deslamagem que exibe o menor volume de quartzo $(64,53 \%)$ e os maiores volumes de óxidos e hidróxidos de ferro $(28,58 \%)$ e de minerais acessórios $(6,68 \%)$.

Tabela 1- Composições mineralógicas quantitativas dos rejeitos.

\begin{tabular}{cccc}
\hline \multirow{2}{*}{ Minerais } & RF & RSF & RSG \\
\cline { 2 - 4 } & $<0,044 \mathrm{~mm}$ & $<0,044 \mathrm{~mm}$ & $<0,044 \mathrm{~mm}$ \\
\hline Quartzo & 67,78 & 54,88 & 64,53 \\
Hematita & 13,46 & 12,35 & 14,22 \\
Goethita & 6,97 & 15,31 & 6,4 \\
Magnetita & 5,59 & 3,91 & 7,96 \\
Csulinita & 1,11 & 2,1 & 1,31 \\
Muscovita & 0,65 & 1,75 & 1,02 \\
Biotita & 0,29 & 1,41 & 0,20 \\
Ferrocaparpolita & 0,26 & 1,04 & 0,41 \\
Cromoferrita & 0,20 & 1,32 & 1,52
\end{tabular}

Pela técnica de minerografia quantitativa, executada através da contagem de pontos em microscópio ótico foi possível verificar que os padrões identificados dos rejeitos, bem como a proporção de volume. A tabela 2 e 3 mostra os dados obtidos nessa análise.
Tabela 2. Quantificação mineralógica dos rejeitos de flotação e de separação magnética dos grossos obtida por minerografia quantitativa.

\begin{tabular}{ccc}
\hline \multirow{2}{*}{ Minerais } & RF & RSG \\
\cline { 2 - 3 } & $<0,044 \mathrm{~mm}$ & $<0,044 \mathrm{~mm}$ \\
\hline Hematita & 2,15 & 31,24 \\
Goethita & 0,00 & 3,35 \\
Quartzo & 97,31 & 59,97 \\
Ovtros & 0,54 & 6,96
\end{tabular}

Tabela 3. Quantificação mineralógica do rejeito da separação magnética dos finos e deslamagem por minerografia quantitativa.

\begin{tabular}{cc}
\hline Minerais & RSF \\
\cline { 2 - 2 } & $<0,044 \mathrm{~mm}$ \\
\hline Hematita & 13,06 \\
Goethita & 10,42 \\
Magnetita & 0,00 \\
Quartzo & 69,71 \\
Ovtros & 6,41 \\
\hline
\end{tabular}

As diferenças nas proporções das frações volumétricas entre os resultados obtidos na análise do sistema de mineralogia automatizada e no método de minerografia quantitativa são aceitáveis, pois ambos os métodos admitem níveis de confiança para todas as medidas efetuadas. Além de diferenças associadas aos níveis de confiança previamente estabelecidos, variações podem estar relacionadas ao fato de que o sistema calcula as frações de volume dos minerais, entre outras especificidades - como fração em massa e frequência de grãos e área de superfície - a partir do número total de pixels identificados de cada fase mineral da amostra. Como a resolução utilizada na aquisição dos dados foi definida em $10 \mu \mathrm{m}$, cada ponto da área de análise selecionada teve sua composição química determinada e devidamente associada ao mineral correspondente; cada ponto foi, posteriormente, computado para compor a fração de volume total do mineral em questão, independentemente da sua condição de ocorrência, associado à partículas de outros minerais na forma de grão, inclusão ou pequenas variações composicionais, resultando, por vezes, em valores superestimados da real quantidade de partículas livres, contabilizadas pela técnica de minerografia.

Em casos de discrepâncias excessivas, em que há diferenças significativas na proporção de minerais de composições extremas, como no caso dos resultados obtidos por ambas as técnicas para o rejeito de flotação, 0 erro encontra-se possivelmente vinculado à 
imprecisões na contagem de pontos por minerografia quantitativa, em função essencialmente da faixa considerada, que é muito fina. Uma vez que, o sistema TIMA-MIRA não produz erros relevantes para minerais com regras de classificação definidas.

\section{Discussão e Conclusões}

Através do sistema TIMA-MIRA foi possível qualificar e quantificar os principais óxidos e hidróxidos de ferro (hematita, magnetita e goethita), além de outros minerais (pirolusita, caulinita, albita, biotita, muscovita, cromoferrita, ferrocarfolita, bannisterita, magnesiogedrita, turmalina, ankerita e dolomita), que constituíam os rejeitos em questão. $A$ análise do comportamento individual de cada resíduo forneceu informações que são úteis na avaliação de sua influência nos diversos métodos de caracterização. Os rejeitos de flotação e separação magnética de grossos apresentaram as maiores frações volumétricas de quartzo, enquanto no rejeito de separação magnética de finos e deslamagem ocorreram, relativamente, elevadas frações volumétricas de óxi-hidróxidos de ferro e de outras espécies minerais. Essas diferenças de composição mineralógica entre os rejeitos são resultantes do fluxo de processos de concentração utilizados, que explica ainda a tendência do aumento de frações volumétricas de óxi-hidróxidos de ferro e a diminuição da fração volumétrica de quartzo com o decréscimo da granulometria em um mesmo tipo de rejeito. Os resultados obtidos neste trabalho estão em conformidade com os resultados obtidos em trabalhos anteriores, por meio da difratometria de raios $\mathrm{X}$ e da minerografia quantitativa e foram adquiridos em um período de tempo rápido para a resolução utilizada.

\section{Agradecimentos}

À Universidade Federal de Ouro Preto, ao Nanolab da Redemat e à Fundação Gorceix.

\section{Referências}

FEl 2015. Disponível em<http://www.fei.com/> Acesso em:27 de maio de 2015.

Haberlah. 2011. Automated Mineralogy publication trends. Disponível em <http://automatedmineralogy. blogspot.com.br> Acesso em 24 maio de 2015.

Petruk W., 1989. The MP-SEM-IPS Analysis System. In: W. Petruk (ed). Short Course on Image Analysis Applied to Mineral and Earth Sciences. Ottawa, Mineralogical Association of Canada, 106-118.

Sutherland D. N., Gottlieb P. 1991. Application of automated quantitative mineralogy in mineral processing. Minerals Engineering, 4(7): 753-762.
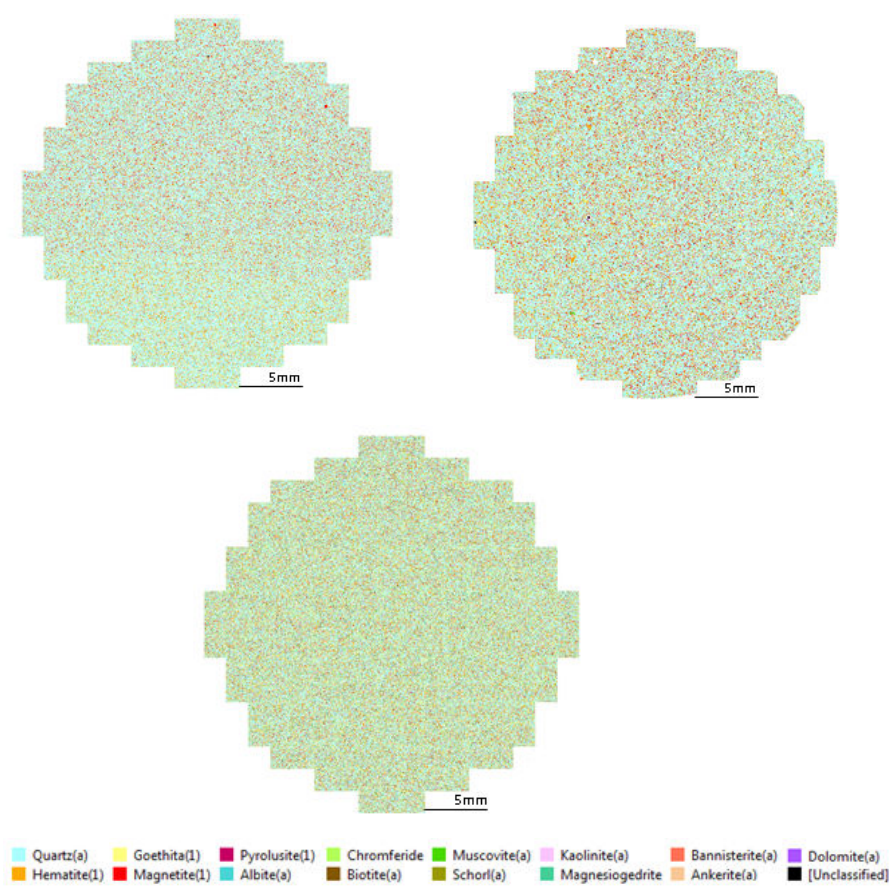

Figura 1. Imagens mineralógicas das amostras dos rejeitos de flotação, da separação magnética dos grossos e da separação magnética dos finos e deslamagem $(<0,044 \mathrm{~mm})$ obtidas pela análise no sistema TIMA-MIRA.

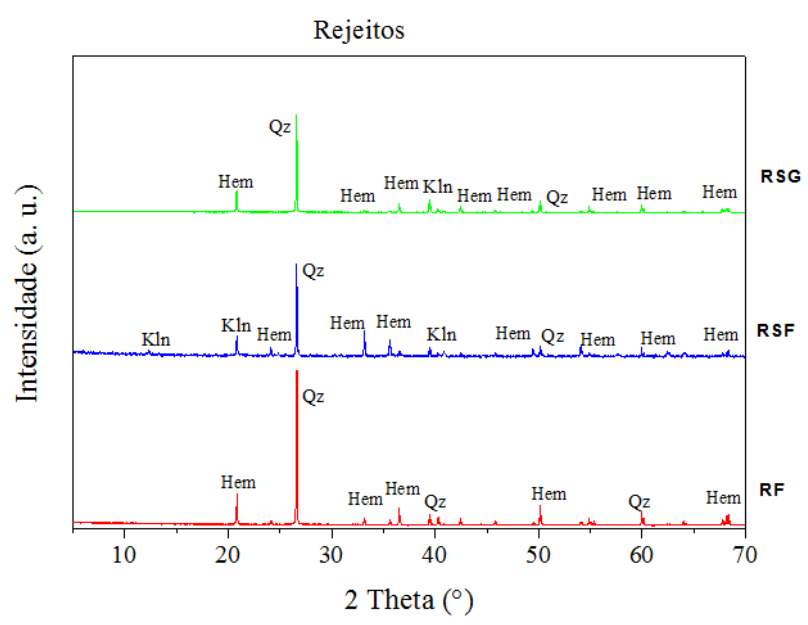

Figura 2. Padrões difratométricos: (RF) rejeitos de flotação, (RSG) rejeitos de separação magnética de grossos e (RSF) rejeitos de separação magnética de finos. 